\title{
Ultrasound-accelerated catheter-directed thrombolysis for the prevention of post-thrombotic syndrome
}

Citation for published version (APA):

Notten, P. (2020). Ultrasound-accelerated catheter-directed thrombolysis for the prevention of postthrombotic syndrome. [Doctoral Thesis, Maastricht University]. ProefschriftMaken Maastricht. https://doi.org/10.26481/dis.20201126pn

Document status and date:

Published: 01/01/2020

DOI:

10.26481/dis.20201126pn

Document Version:

Publisher's PDF, also known as Version of record

\section{Please check the document version of this publication:}

- A submitted manuscript is the version of the article upon submission and before peer-review. There can be important differences between the submitted version and the official published version of record. People interested in the research are advised to contact the author for the final version of the publication, or visit the DOI to the publisher's website.

- The final author version and the galley proof are versions of the publication after peer review.

- The final published version features the final layout of the paper including the volume, issue and page numbers.

Link to publication

\footnotetext{
General rights rights.

- You may freely distribute the URL identifying the publication in the public portal. please follow below link for the End User Agreement:

www.umlib.nl/taverne-license

Take down policy

If you believe that this document breaches copyright please contact us at:

repository@maastrichtuniversity.nl

providing details and we will investigate your claim.
}

Copyright and moral rights for the publications made accessible in the public portal are retained by the authors and/or other copyright owners and it is a condition of accessing publications that users recognise and abide by the legal requirements associated with these

- Users may download and print one copy of any publication from the public portal for the purpose of private study or research.

- You may not further distribute the material or use it for any profit-making activity or commercial gain

If the publication is distributed under the terms of Article $25 \mathrm{fa}$ of the Dutch Copyright Act, indicated by the "Taverne" license above, 


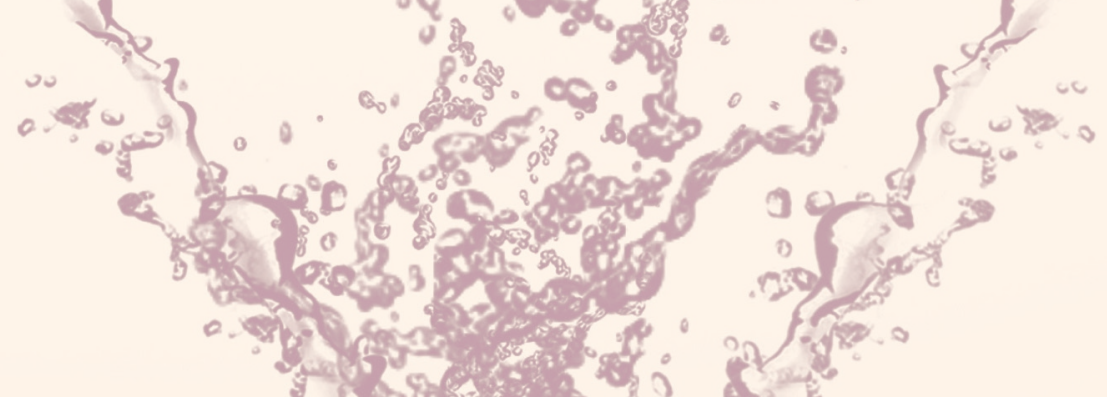

Nederlandse samenvatting 
194 | Nederlandse samenvatting 
Diep veneuze trombose is een ernstige aandoening die een substantieel deel van de populatie op enig moment gedurende hun leven zal treffen ${ }^{1,2}$ : het is zelfs de meest voorkomende cardiovasculaire aandoening na coronair vaatlijden en beroertes..$^{3,4}$ Bovendien zal 40 tot $60 \%$ van deze patiënten een zekere mate van post-trombotisch syndroom ontwikkelen bestaande uit klachten van oedeem, pijn, vermoeidheid, huidveranderingen en uiteindelijk veneuze ulceratie van het post-trombotische been. 5 Vanwege het ontbreken van curatieve behandelmogelijkheden is de huidige behandeling puur symptomatisch, derhalve is het voorkómen van het ontstaan van deze klachten het meest wenselijk.

Uitgaande van het concept van veneuze hypertensie (als gevolg van veneuze flow obstructie en veneuze insufficiëntie) als de onderliggende pathofysiologie voor posttrombotisch syndroom wordt de "open vein hypothesis" geopperd als potentiële behandelstrategie waarmee het ontwikkelen van post-trombotisch syndroom kan worden voorkómen. ${ }^{7,8}$

Normaliter zal na een diep veneuze trombose spontane resolutie van het trombus optreden met rekanalisatie van de aangedane vaatsegmenten. ${ }^{9}$ In hoeverre dit rekanalisatieproces succesvol verloopt, bepaalt vervolgens het risico op post-trombotisch syndroom waarbij een beperking van de resterende veneuze obstructie geassocieerd is met een lager risico. ${ }^{10}$ Aangezien het proces van spontane rekanalisatie minder succesvol is gebleken in trombi gelocaliseerd in het iliofemorale traject, neemt het risico op posttrombotisch syndroom in deze patiënten toe. ${ }^{11}$ Rekanalisatie is een complex proces bestaande uit een nauwkeurig gecoördineerd samenspel van verschillende mechanismen waaronder inflammatie. ${ }^{9} \mathrm{Bij}$ een suboptimaal verloop van dit rekanalisatieproces kan dit leiden tot intraluminale fibrose, hermodellering van de veneuze vaatwand en/of schade aan de veneuze kleppen met tot gevolg een persisterende veneuze flow obstructie als ook veneuze insufficiëntie. Dit kan vervolgens leiden tot veneuze hypertensie die zich klinisch presenteert als het post-trombotisch syndroom. De huidige standaard post-trombotische behandelstrategiën ${ }^{12,13}$ zijn niet gericht op het ondersteunen of versnellen van het rekanalisatieproces en zijn derhalve ook niet succesvol in de preventie van posttrombotisch syndroom.

In 2009 toonden Enden et al. als onderdeel van de CaVenT-studie aan dat kathetergestuurde trombolyse als aanvulling op de standaard antistollingstherapie een succesvolle bijdrage leverde aan het herstellen van de veneuze doorgankelijkheid na een acute iliofemorale diep veneuze trombose. ${ }^{14}$ In 2012 presenteerden ze de resultaten betreffende het preventieve effect van deze additionele behandeling op het ontstaan van post-trombotisch syndroom waar, bij een follow-up duur van twee jaar, een absolute risicoreductie van $14,4 \%$ werd gezien ten opzichte van patiënten die alleen de standaard behandeling kregen. ${ }^{15}$ Dit bleek een belangrijke doorbraak te zijn met potentieel verstrekkende gevolgen voor de invulling van post-trombotische zorg in de acute fase, zeker toen de onderzoekers aantoonden dat het preventieve effect van additionele katheter-gestuurde trombolyse bij uitbreiding van de follow-up vijf jaar verder was opgelopen tot $28 \% .^{16}$ 
Helaas kon dit significante preventieve effect niet worden bevestigd door een tweede randomized controlled trial, de ATTRACT-studie, waarbij additionele pharmacomechanische katheter-gestuurde trombolyse werd vergeleken met standaard antistollingsbehandeling. ${ }^{17}$ De incidentie van post-trombotisch syndroom bleek bij een follow-up duur van twee jaar gelijk in beide behandelgroepen: $47 \%$ in de groep met additionele pharmacomechanische katheter-gestuurde trombolyse versus $48 \%$ in de controlegroep met de standaard behandeling. Deze uitkomsten leidden logischerwijs opnieuw tot de vraag of additionale katheter-gestuurde trombolyse daadwerkelijk een preventief effect had op de ontwikkeling van post-trombotisch syndroom.

Hoofdstuk 2 presenteert de resultaten van de CAVA-studie, een derde randomized controlled trial waarbij onderzocht werd of additionele katheter-gestuurde trombolyse na een acute iliofemorale diep veneuze trombose de ontwikkeling van post-trombotisch syndroom kan voorkomen. Deze studie was specifiek gericht op patiënten met iliofemorale diep veneuze trombose aangezien spontane rekanalisatie bij deze groep patiënten minder waarschijnlijk is en derhalve de geanticipeerde voordelen voor deze patiënten naar verwachting voldoende op zouden wegen tegen het verhoogde bloedingsrisico. Na een follow-up duur van één jaar bleek er echter geen significant verschil te zijn in de proportie patiënten met post-trombotisch syndroom in beide behandelarmen: $29 \%$ in de groep met de additionele behandeling versus $35 \%$ in de groep met enkel de standaard behandeling. Bij de interpretatie van onze resultaten en voor het maken van een vergelijking met de resultaten van zowel de CaVenT en ATTRACT-studie om de waarde van additionele katheter-gestuurde trombolyse voor de preventie van posttrombotisch syndroom te kunnen bepalen, moet met een aantal belangrijke zaken rekening worden gehouden.

Ten eerste worden er in de huidige literatuur verschillende definities voor posttrombotisch syndroom gebruikt wat vergelijking van resultaten bemoeilijkt. De oorspronkelijke definitie zoals opgesteld door Villalta et al. is gebaseerd op het ontwikkelen van veneuze ulceratie of een verhoogde Villalta-score van 5 of hoger bij twee opeenvolgende beoordelingen met minimaal drie maanden tussenliggend en waarbij de eerste beoordeling niet eerder mag plaatsvinden dan drie maanden na het acute event. ${ }^{18}$ Een eenmalig verhoogde Villalta-score of het optreden van veneuze ulceratie zes maanden of langer na de acute diep veneuze trombose is voldoende voor het stellen van de diagnose volgens de definitie zoals voorgesteld door de International Society of Thrombosis and Haemostasis (ISTH). ${ }^{19}$ De primaire uitkomst van de CAVA-studie betrof de oorspronkelijke definitie terwijl de uitkomsten volgens de ISTH-definitie als secundaire uitkomsten werden gepresenteerd. Om de uitkomsten van de verschillende studies met elkaar te vergelijken, kunnen het best de resultaten volgens de ISTH-definitie gebruikt worden aangezien zowel de CaVenT als de ATTRACT definities hanteerden die hieraan gelijkwaardig zijn. Hierbij moet worden opgemerkt dat de ISTH-definitie leidt tot een overschatting van het aantal diagnoses. ${ }^{20}$

Ten tweede is de incidentie van post-trombotisch syndroom in de controlegroep van de CaVenT-studie (55.6\%) opmerkelijk hoger dan in de ATTRACT en CAVA (respectievelijk 48\% en 44\%). Aangezien het percentage patiënten met post-trombotisch syndroom in de interventiegroepen van de verschillende studies enigszins vergelijkbaar is $(41.1 \%$ in de CaVenT, $47 \%$ in de ATTRACT en $42 \%$ in de CAVA), moet men de mogelijkheid overwegen 
dat het therapeutische voordeel dat wordt gevonden in de CaVenT-studie voornamelijk gedreven is door het hoge percentage diagnoses in de controlegroep. Alhoewel het niet statistisch significant verschilt, kan men speculeren dat de hoge incidentie van posttrombotisch syndroom in de controlegroep van de CaVenT-studie voort komt uit een minder adequate antistollingsbehandeling (het percentage patiënten dat bij 24 maanden follow-up duur binnen hun therapeutische streefwaarden zit: $50.0 \%$ versus $65.4 \%$ ) en minder compliantie betreffende de compressie therapie (het percentage patiënten dat bij 24 maanden follow-up duur dagelijks compressiekousen gebruikt: $51.5 \%$ versus $63.3 \%$ ) in vergelijking met de patiënten die additionele katheter-gestuurde trombolyse ondergingen.

De CAVA-studie heeft het geanticipeerde voordeel van additionele katheter-gestuurde trombolyse dat verwacht werd op basis van de "open vein hypothesis" en de eerder gepubliceerde resultaten van de CaVenT-studie niet kunnen aantonen. In dit proefschrift wordt vervolgens de invloed van verschillende potentieel hieraan bijdragende factoren geëvalueerd zoals daar zijn de follow-up duur (hoofdstuk 3), de mate van technisch succes van de interventie (hoofdstuk 4), de post-interventionele antitrombotische behandeling (hoofdstukken 5 en 6) en de patiëntselectie (hoofdstuk 7).

Een van de belangrijkste commentaren op het design van de CAVA-studie betrof de follow-up duur van één jaar ten opzichte van de tweejarige follow-up duur in de andere studies. Alhoewel het post-trombotisch syndroom meestal ontstaat in het eerste jaar na het acute event kan de incidentie nog gedurende vele jaren oplopen. ${ }^{6,15}$ Het preventieve effect van additionale katheter-gestuurde trombolyse gevonden in de CaVenT-studie werd bovendien pas evident na een follow-up duur van twee jaar en nam nog verder toe bij verlenging van de follow-up duur. ${ }^{15,16}$ Derhalve werd, zoals gepresenteerd in hoofdstuk 3, een analyse verricht van de lange termijn resultaten van de CAVA-studie. Hierbij werd, met een mediane follow-up duur van bijna 3,5 jaar, geen significant preventief effect gevonden op het ontwikkelen van post-trombotisch syndroom bij gebruik van de oorspronkelijke definitie van de Villalta-score: post-trombotisch syndroom werd gediagnosticeerd bij $30.6 \%$ van de patiënten in de interventiegroep versus $44.8 \%$ van de patienten in de controlegroep. Echter, de ontwikkeling van post-trombotisch syndroom gediagnosticeerd volgens de ISTH-definitie was wel significant lager in de interventiegroep ten opzichte van de controlegroep, respectievelijk $46.8 \%$ versus $69.0 \%$ ( $p=0.01$ ). Zoals verwacht berustte dit verschil met name op het hogere aantal patiënten met een milde presentatie van post-trombotisch syndroom volgens de ISTH-definitie $(\mathrm{P}=0.01)$. Overigens werd in geen van beide groepen een klinisch relevante verbetering van de kwaliteit van leven gezien ten opzichte van de éénjaars follow-up.

Volgens de "open vein hypothesis" is een snel en adequaat herstel van de veneuze doorgankelijkheid en flow cruciaal in het voorkómen van post-trombotisch syndroom. Daarom werd een subanalyse verricht waarbij de mate van het technische succes van de interventie werd meegenomen in de vergelijkingen. Hoofdstuk 4 laat zien dat succesvolle rekanalisatie, gedefinieerd als herstel van de veneuze doorgankelijkheid tot $\geq 90 \%$, slechts bereikt werd in $53.2 \%$ van de patiënten waarbij additionele katheter-gestuurde trombolyse was geïnitieerd. Bij een follow-up duur van één jaar werd geen significant verschil gevonden in de ontwikkeling van post-trombotisch syndroom (op basis van de 
ISTH-definitie) tussen patiënten die succesvolle rekanalisatie hadden ondergaan en patiënten die enkel de standaard antistollingsbehandeling hadden gekregen. Echter, patiënten met een succesvolle rekanalisatie rapporteerden een lagere ernst van de klachten en bereikten een hogere algemene kwaliteit van leven. De kans op een succesvolle rekanalisatie was hoger bij een kortere duur van klachten ten tijde van studieinclusie $(P=0.05)$, het verrichten van aanvullende procedures $(P<0.001)$ en stent plaatsing $(P<0.001)$.

In de laatste jaren hebben experimenteel en emperisch onderzoek bijgedragen aan een verdere ontwikkeling van mogelijkheden voor het bereiken van vroege rekanalisatie. Deze innovaties betreffen nieuwe beeldvormingstechnieken (magnetische resonantie venografie [MRV], intraveneuze ultrasound [IVUS]), ontwikkeling en verbetering van endovasculaire behandelstrategiën en locale trombolyse, ontwikkeling van verschillende methoden voor endovasculaire thrombectomie (pharmacologisch, mechanisch, pharmacomechanisch) en de introductie van 'dedicated' veneuze stents. Als aanvulling op het creëren van de optimale omstandigheden voor vroege rekanalisatie dient ook aandacht te worden besteed aan het optimaliseren van peri-interventionele factoren (zoals het definiëren van adequate behandelindicaties en criteria voor patiëntselectie, het onderzoeken van de waarde en het specificeren van peri-interventioneel antitrombotisch beleid, het verbeteren van protocollen voor veneuze trombolyse, het bepalen van indicaties voor aanvullende procedures).

Na het verkrijgen van veneuze doorgankelijkheid middels een technisch succesvolle rekanalisatie is het van groot belang deze doorgankelijkheid te behouden. Aangezien recidiverende diep veneuze trombose een bekende risicofactor is voor het ontwikkelen van post-trombotisch syndroom en de ernst van de klachten ${ }^{5,21-25}$ zou men kunnen veronderstellen dat een in-stent trombose een negatieve impact heeft op de klinische uitkomsten door terugkeer van klachten en een mogelijke noodzaak tot re-interventie. In de CAVA-studie (hoofdstuk 3) werden in totaal 12 in-stent tromboses gezien in de patiëntengroep met additionele katheter-gestuurde trombolyse. Dit aantal droeg substantieel bij aan het nummerieke verschil in recidiverende veneus trombo-embolische events: 17 events in 77 patiënten uit de interventiegroep versus 7 events in 75 patiënten uit de controlegroep. Men zou kunnen speculeren dat het optreden van een in-stent trombose het daadwerkelijke behandelingseffect als gevolg van een technisch succesvolle rekanalisatie ongedaan maakt en vertroebelt. Met andere woorden, zou additionale kathether-gestuurde trombolyse wel leiden tot preventie van het post-trombotisch syndroom indien het optreden van in-stent tromboses voorkómen had kunnen worden?

Het risico op een (recidiverend) veneus thrombo-embolisch event kan worden verklaard door de trias van Virchow: hypercoagulabiliteit, endotheelschade en een verstoorde flow. De huidige post-trombotische behandelstrategiën verlagen het risico op deze recidiverende veneus trombo-embolische events middels het gebruik van antitrombotische therapie. Veneuze stentplaatsing is een relatief nieuwe maar in toenemende mate toegepaste behandelmodaliteit waarmee een obstructie van de veneuze flow, zowel als gevolg van post-trombotische synechiae als bij non-trombotische oorzaken zoals compressie syndromen, agenesie of anatomische anomaliën, gecorrigeerd 
kan worden. Echter, het verrichten van een veneuze stentplaatsing induceert mogelijke hypercoagulabiliteit (als gevolg van de post-operatieve pro-trombotische status), endotheel schade (als gevolg van iatrogene rekanalisatie, de-endothelialisatie en het plaatsen van een corpus alienum in het vaatstelsel) als ook een verstoring van de veneuze flow (als gevolg van immobilisatie, inadequate positionering van de stent, stentfracturen of een insufficiënte veneuze inflow). Het risico op een iatrogene oorzaak van verstoorde veneuze flow neemt af vanwege de toenemende ervaring, de ontwikkeling van 'dedicated' veneuze materialen en instrumenten evenals de mogelijkheid tot hybride procedures om een voldoende veneuze inflow veilig te stellen middels endophlebectomie (chirurgisch verwijderen van intraluminale synechia) en/of het creëren van een arterio-veneuze fistel. ${ }^{26-28}$ Aangezien binnen enkele weken na veneuze stentplaatsing re-endothelialisatie optreedt ${ }^{29}$, is het probleem van endotheelschade slechts tijdelijk en kan, afgaande op de ervaringen met arteriële stents ${ }^{30}$, overbrugd worden middels antitrombotische therapie waarmee tegelijkertijd eventuele hypercoagulabiliteit behandeld wordt.

Ondanks dat veneuze stentplaatsingen in toenemende mate worden uitgevoerd, ontbreekt het aan een evidence-based richtlijn betreffende de waarde van postinterventionele antitrombotische therapie en hoe het optimale behandelingsregime eruit zou moeten zien. Er wordt een grote variatie aan antitrombotische regimes toegepast door artsen over de hele wereld. ${ }^{31} \mathrm{Al}$ decennialang worden vitamine-K antagonisten gebruikt voor antitrombotische therapie wat heeft geleid tot veel ervaring en evidencebased kennis over diens effectiviteit en risicos bij de meeste artsen. Echter bij de introductie van de nieuwe directe orale antistollingsmiddelen kwamen er nieuwe behandelmogelijkheden beschikbaar die patiëntvriendelijker geacht werden in het gebruik, minder gevoelig waren voor farmacokinetische variatie en bovendien resulteerden in een lager risico op intracraniële bloedingen. Tot op heden ontbreekt het aan evidence over de waarde van behandeling met directe orale antistollingsmiddelen rondom veneuze stent plaatsing.

De systematic review in hoofdstuk 5 was gericht op het vaststellen van het optimale postinterventionele antitrombotische beleid na een iliofemorale veneuze stentplaatsing in patiënten met (een geschiedenis van) diep veneuze trombose. Vanwege het ontbreken van voldoende vergelijkbare data kon geen meta-analyse worden verricht en werd een systematisch overzicht gegeven van de beschreven post-interventionele antitrombotische behandelregimes. Deze bevindingen, of juist het ontbreken daarvan, geven het hiaat in kennis betreffende post-interventionele antitrombotische therapie weer en benadrukken de noodzaak voor klinisch onderzoek om een evidence-based richtlijn op te kunnen stellen voor het optimaliseren van post-interventioneel beleid en behandeluitkomsten.

Slechts twee studies vergeleken behandeluitkomsten tussen verschillende antitrombotische regimes na iliofemorale veneuze stentplaatsing in patiënten met (een geschiedenis van) diep veneuze trombose.

De studie van Sebastian et al. ${ }^{32}$ was de enige studie die behandeluitkomsten vergeleek tussen het gebruik van twee verschillende antitrombotische geneesmiddelen na iliofemorale veneuze stentplaatsing in patiënten met (een geschiedenis van) diep veneuze trombose: vitamine-K antagonisten versus rivaroxaban (direct oraal antistollingsmiddel, Xa-remmer). Aangezien zij geen verschil in effectiviteit of veiligheid vonden tussen beide behandelgroepen worden de klinische uitkomsten mogelijk niet beïnvloed door het type antitrombotica. De studie gepresenteerd in hoofdstuk 6 laat echter zien dat de kwaliteit 
van de antistollingsbehandeling met vitamine- $K$ antagonisten geassocieerd is met het risico op in-stent trombose. Er werden geen aanwijzingen gevonden voor dat een hogere streefwaarde van de International Normalized Ratio (INR) tussen de 2.5-4.0 leidde tot een betere bescherming tegen het optreden van in-stent tromboses. Om het risico op in-stent tromboses te beperken, dient een stabiele INR met een streefwaarde tussen de 2.0-3.0 en een 'Time within Therapeutic Range' van $\geq 50 \%$ te worden behaald. Het is mogelijk dat behandeling met directe orale antistollingsmiddelen, vanwege hun lage variabiliteit in antistollingsactiviteit, zelfs nog effectiever is in deze setting. Echter of de geregistreerde doseringen van deze middelen ook daadwerkelijk voldoende zijn om in-stent tromboses te voorkómen zal onderzocht moeten worden in klinische trials.

Behalve het voldoen aan technische randvoorwaarden, is het verder van belang een adequate selectie toe te passen om de patiënten te selecteren die het meest zullen profiteren van de voorgestelde behandeling. Er zijn veel verschillende risicofactoren die het risico op het ontwikkelen van recidiverende diep veneuze trombose of in-stent trombose kunnen beïnvloeden. Ondanks dat het nooit geobjectiveerd is, wordt op basis van de trias van Virchow gehypothetiseerd dat een (pre-existente) obstructie van de veneuze flow mogelijk een van deze bijdragende factoren zou kunnen zijn en daarmee direct suggereert dat aanwezigheid van zo'n obstructie indicatie is voor preventieve veneuze stentplaatsing. Hoofdstuk 7 laat de resultaten zien van een exploratoir casecontrol onderzoek waarbij de prevalentie van veneuze flow obstructies (zijnde als gevolg van extraluminale compressie of anatomische anomaliën) werd vergeleken tussen patiënten met een recidiverende diep veneuze trombose en patiënten vrij van recidieven. De prevalentie van pre-existente veneuze flow-obstructies verschilde niet tussen beide groepen waardoor er geen indicaties zijn voor de waarde van preventieve veneuze stentplaatsing in patiënten met acute diep veneuze trombose en een gelijktijdige preexistente veneuze obstructie.

Concluderend, de onderzoeksresultaten gepresenteerd in dit proefschrift tonen aan dat de huidig beschikbare gegevens het gebruik van additionele katheter-gestuurde trombolyse voor de preventie van post-trombotisch syndroom na een iliofemorale diep veneuze trombose niet ontegenzeggelijk ondersteunen. Er is meer onderzoek nodig om een gedegen en definitief statement hierover te kunnen formuleren. Hierbij zou de nadruk niet alleen moeten liggen op het aantonen van een potentieel preventief effect van additionele katheter-gestuurde trombolyse maar ook op manieren om de potentie van deze behandelmethode te optimaliseren (bijv. verbetering van behandelprotocollen en ontwikkeling van materialen die hogere technisch slagingspercentages faciliteren). Daarnaast moet onderzoek worden verricht naar de manier waarop de eventueel verworven voordelen van trombolyse (met of zonder veneuze stent plaatsing) voor de lange termijn kunnen worden behouden (bijv. door het voorkomen van in-stent tromboses) en moet worden bepaald voor welke patiënten additionele kathetergestuurde trombolyse het meest profijtelijk is en de voordelen de mogelijke risico's overtreffen (bijv. het formuleren van heldere behandelindicaties, het identificeren van patiëntgebonden risicofactoren en het verrichten van een kosten-effectiviteitsanalyse). 


\section{Referentielijst}

1 Browse NL, Burnand KG, Lea Thomas M. Deep vein thrombosis: pathology, diagnosis and treatment. In: Browse NL, Burnand KG, Irvine AT, Wilson NM, eds. Diseases of the veins, 2nd edn. London, England: Edward Arnold, 1999: 443-74.

2 White RH. The epidemiology of venous thromboembolism. Circulation 2003; 107 (suppl 1): 14-8.

3 Jaff MR, McMurtry MS, Archer SL, et al. Management of massive and submassive pulmonary embolism, iliofemoral deep vein thrombosis, and chronic thromboembolic pulmonary hypertension: a scientific statement from the American Heart Association [published correction appears in Circulation. 2012 Aug 14;126(7):e104] [published correction appears in Circulation. 2012 Mar 20;125(11):e495]. Circulation. 2011;123(16):1788-1830. doi:10.1161/CIR.0b013e318214914f.

4 Cohen AT, Agnelli G, Anderson FA, et al; VTE Impact Assessment Group in Europe (VITAE). Venous thromboembolism (VTE) in Europe. The number of VTE events and associated morbidity and mortality. Thromb Haemost 2007;98(4):756-764

$5 \quad$ Kahn SR, Shrier I, Julian JA, et al. Determinants and time course of the postthrombotic syndrome after acute deep venous thrombosis. Ann Intern Med 2008; 149: 698-707.

6 Schulman S, Lindmarker P, Holmstrom M, et al. Post-thrombotic syndrome, recurrence, and death 10 years after the first episode of venous thromboembolism treated with warfarin for 6 weeks or 6 months. J Thromb Haemost 2006; 4: 734-42.

$7 \quad$ Henke PK, Comerota AJ. An update on etiology, prevention, and therapy of postthrombotic syndrome. J Vasc Surg. 2011 Feb;53(2):500-9. doi: 10.1016/j.jvs.2010.08.050. Epub 2010 Dec 3. Review. PubMed PMID: 21129900.

8 Comerota AJ, Paolini D. Treatment of acute iliofemoral deep venous thrombosis: a strategy of thrombus removal. European journal of vascular and endovascular surgery : the official journal of the European Society for Vascular Surgery. 2007;33(3):351-360; discussion 361-352.

9 Ten Cate-Hoek AJ, Henke PK, Wakefield TW. The post thrombotic syndrome: Ignore it and it will come back to bite you. Blood Rev. 2016 Mar;30(2):131-7. doi: 10.1016/j.blre.2015.09.002. Epub 2015 Oct 9. Review. PubMed PMID: 26462885.

10 Amin EE, Bistervels IM, Meijer K, et al. Reduced incidence of vein occlusion and postthrombotic syndrome after immediate compression for deep vein thrombosis. Blood. 2018;132(21):2298-2304. doi:10.1182/blood-2018-03-836783.

11 Tick LW, Doggen CJM, Rosendaal FR, et al. Predictors of the post-thrombotic syndrome with noninvasive venous examinations in patients 6 weeks after a first episode of deep vein thrombosis. J Thromb Haemost 2010; 8: 2685-2692.

12 Appelen D, van Loo E, Prins MH, Neumann MH, Kolbach DN. Compression therapy for prevention of post-thrombotic syndrome. The Cochrane database of systematic reviews. 2017;9:Cd004174. Kearon C, Akl EA, Ornelas J, et al. Antithrombotic Therapy for VTE Disease: CHEST Guideline and Expert Panel Report. Chest. 2016;149(2):315-52.

14 Enden T, Kløw NE, Sandvik L, et al. Catheter-directed thrombolysis vs. anticoagulant therapy alone in deep vein thrombosis: results of an open randomized, controlled trial reporting on short-term patency. J Thromb Haemost. 2009 Aug;7(8):1268-75. doi: 10.1111/j.1538-7836.2009.03464.x. Epub 2009 Apr 30. PubMed PMID: 19422443.

15 Enden T, Haig Y, Kløw NE, et al. Long-term outcome after additional catheter-directed thrombolysis versus standard treatment for acute iliofemoral deep vein thrombosis (the CaVenT study): a randomized controlled trial. Lancet. 2012 Jan 7;379(9810):31-8. doi: 10.1016/S0140-6736(11)61753-4. Epub 2011 Dec 13. PubMed PMID: 22172244.

16 Haig Y, Enden T, Grøtta O, et al. Post-thrombotic syndrome after catheter-directed thrombolysis for deep vein thrombosis (CaVenT): 5-year follow-up results of an open-label, randomized controlled trial. Lancet Haematol. 2016 Feb;3(2):e64-71. doi: 10.1016/S2352-3026(15)00248-3. Epub 2016 Jan 6. PubMed PMID: 26853645.

17 Vedantham S, Goldhaber SZ, Julian JA, et al. Pharmacomechanical Catheter-Directed Thrombolysis for Deep-Vein Thrombosis. N Engl J Med. 2017 Dec 7;377(23):2240-2252. doi: 10.1056/NEJMoa1615066. PubMed PMID: 29211671; PubMed Central PMCID: PMC5763501. Villalta S, Bagatella P, Piccioli A, Lensing AW, Prins MH, Prandoni P. Assessment of validity and reproducibility of a clinical scale for the post-thrombotic syndrome. Haemostasis 1994; 24: 158a (abstr).

19 Kahn SR, Partsch H, Vedantham S, Prandoni P, Kearon C; Subcommittee on Control of Anticoagulation of the Scientific and Standardization Committee of the International Society on Thrombosis and 
Haemostasis. Definition of post-thrombotic syndrome of the leg for use in clinical investigations: a recommendation for standardization. J Thromb Haemost. 2009;7(5):879-883. doi:10.1111/j.15387836.2009.03294.x

Ten Cate-Hoek AJ. Prevention and treatment of the post-thrombotic syndrome. Res Pract Thromb Haemost. 2018;2(2):209-219. Published 2018 Mar 10. doi:10.1002/rth2.12085. Bouman AC, Smits JJM, Ten Cate H, Ten Cate-Hoek AJ. Markers of coagulation, fibrinolysis and inflammation in relation to post-thrombotic syndrome. J Thromb Haemost. 2012;10:1532-1538. Labropoulos N, Jen J, Jen H, Gasparis AP, Tassiopoulos AK. Recurrent deep vein thrombosis: long-term incidence and natural history. Ann Surg. 2010;251:749-753. van Dongen CJ, Prandoni P, Frulla M, Marchiori A, Prins MH, Hutten BA. Relation between quality of anticoagulant treatment and the development of the postthrombotic syndrome. J Thromb Haemost. 2005;3:939-942.

Prandoni $P$, Lensing AWA, Prins MH, Frulla M, Marchiori A, Bernardi E, Tormene D, Mosena L, Pagnan A, Girolami A. Below-knee elastic compression stockings to prevent the post-thrombotic syndrome: a randomized, controlled trial. Ann Intern Med. 2004;141:249-256. Prandoni P, Lensing AWA, Cogo A, Cuppini S, Villalta S, Carta M, Cattelan AM, Polistena P, Bernardi E, Prins $\mathrm{MH}$. The long-term clinical course of acute deep venous thrombosis. Ann Intern Med. 1996;125:1-7. Jalaie H, Schleimer K, Barbati ME, et al. Interventional treatment of postthrombotic syndrome. Gefasschirurgie. 2016;21(Suppl 2):37-44. Epub 2016 Jul 12. PubMed PMID: 27546987; PubMed Central PMCID: PMC4974289. Mahnken AH, Thomson K, de Haan M, O'Sullivan GJ. CIRSE standards of practice guidelines on iliocaval stenting. Cardiovasc Intervent Radiol. 2014 Aug;37(4):889-97. doi: 10.1007/s00270-014-0875-4. Epub 2014 Mar 15. PubMed PMID: 24633533. De Wolf MA, Arnoldussen CW, Wittens $\mathrm{CH}$. Indications for endophlebectomy and/or arteriovenous fistula after stenting. Phlebology. 2013 Mar;28 Suppl 1:123-8. doi: 10.1177/0268355513477063. Review. PubMed PMID: 23482547. Hartung O, Benmiloud F, Barthelemy P, Dubuc M, Boufi M, Alimi YS. Late results of surgical venous thrombectomy with iliocaval stenting. J Vasc Surg. 2008 Feb;47(2):381-7. doi: 10.1016/j.jvs.2007.10.007. PubMed PMID: 18241761. Mackman N. Triggers, targets and treatments for thrombosis. Nature 2008;451 (7181):914-918. Milinis K, Thapar A, Shalhoub J, Davies AH. Antithrombotic therapy following venous stenting: international Delphi consensus. Eur J Vasc Endovasc Surg. 2018;55(4):537-44. Sebastian T, Hakki LO, Spirk D, et al. Rivaroxaban or vitamin-K antagonists following early endovascular thrombus removal and stent placement for acute iliofemoral deep vein thrombosis. Thromb Res. 2018;172:86-93. doi:10.1016/j.thromres.2018.10.027. 